\title{
Why Mobile Payments Fail? Towards a Dynamic and Multi-perspective Explanation
}

\author{
Jan Ondrus \\ ESSEC Business School \\ ondrus@essec.fr
}

\author{
Kalle Lyytinen \\ Case Western Reserve University \\ kalle.lyytinen@,case.edu
}

\author{
Yves Pigneur \\ University of Lausanne \\ yves.pigneur@unil.ch
}

\begin{abstract}
Despite optimistic expectations fast diffusion of mobile payments has not taken place after a decade of trials. Several explanations to this situation have been put forward using several theories and levels of analysis. Due to the complexity and dynamism of the diffusion we need multiple perspectives to account for diffusion challenge. We juxtapose three frameworks into a dynamic analysis framework. We apply the proposed framework to explain three failed introductions of mobile payments in the Swiss market. In particular, a recent ambitious trial is confronted with the proposed framework to detect roots of its failure. Our analysis suggests that market-level and behavioral facets need more attention in future in explaining mobile payment diffusion. To guide future efforts we propose several avenues for further research.
\end{abstract}

\section{Introduction}

With the widespread adoption of mobile phones for voice and text messaging, a recurrent question raised is: what will be the next killer application? Many analysts, consultants, and researchers have focused on this question, and, not surprisingly, mobile payments have often been identified as a good candidate. Being able to pay with a mobile phone that you carry with you anyway looks an obvious alternative given the fact that now over $80 \%$ of Western people carry a mobile phone, and the fast developments in e-/m-commerce and electronic payment technologies. Furthermore, mobile payments are necessary to carry out transactions that involve digital content (e.g., ringtones, news, music). Mobile payments can provide also new payment schemes and services for widely used debit and credit cards.

Despite this promise up to this point only few cases of limited success can be identified in mobile payments. Japan, South Korea, Singapore lead the pack [19] as these countries offer now mobile payment services that can be used in several purchase scenarios, such as manned and unmanned, remote and proximity payments for physical and digital goods. Even though, their deployed technologies and services are more varied and advanced, the usage rates are still low and now wide spread diffusion has taken place [2]. One fundamental reason is that mobile payments require customers to change their behaviors towards tightly ingrained payment habits. Learning from the history of credit card adoption [6] it will take time before the mass-adoption of payment systems is reached. In Europe and the U.S., most solutions have been launched for specific purposes (e.g. digital content, parking, vending machines). These niche markets ensure a relatively secure business case, but the growth potential of these mobile payments remains highly limited.

The reason why most Western countries have not been able to deploy mobile payments in a massive scale has not been scrutinized carefully. It appears that the success of mobile payments depends greatly on the effective alignment between a business model and physical environment in which it will be launched. Our objective in this paper is to examine factors that influence the success of the proposed mobile payment scheme. In particular, we will examine impending factors that lead either to the failure of developing a robust business model, or to the low uptake of the proposed solutions. In previous research [13], we applied multi-criteria decision-making methods (MCDM) to understand what shapes different player's decision making in mobile payment markets. In this study we expand this line of research with an inquiry into institutional, economic and behavioral factors that shape mobile payment provisioning and adoption. To this end we juxtapose three frameworks to analyze mobile payment diffusion. The first framework leans on the economic analysis of the mobile payment markets [1]. The second one looks at strategic and environmental drivers [5]. Finally, the third one focuses on resources and business drivers that shape mobile payment provisioning [3]. 
We apply the frameworks to explore the failure of three Swiss mobile payment cases, which we have been following for about 5 years. Based on our longitudinal research [13], we confront the frameworks with the process and use data derived from the cases. We select one of these cases involving most extensive mobile payment trial data for detailed scrutiny to illustrate why it failed and how it misaligned with a number of critical factors.

We bring our contribution in two fronts. First, by juxtaposing and integrating the frameworks we offer a more encompassing framework for the analysis of the (failed) diffusion of mobile payments. Second, by using the three frameworks together we reveal their weaknesses and strengths and thus help formulating more encompassing frameworks that could be applied to deliver complex mobile payment infrastructures.

In the next section, we briefly summarize previous research into mobile payments, introduce the frameworks, and identify aspects that have not been covered well in the extant research. Then, we describe three Swiss mobile payment cases that are used in the subsequent analysis. Next, we use three frameworks to analyze the cases and, in particular, to describe in detail the failure of one of the cases - the PostFinance payment system. We conclude by outlining three lines for future research. First, we evaluate the benefit of using the three frameworks and reflect on their merits. Second, we look at the Swiss case findings and delineate factors that are likely to influence the failure of similar future systems. Third, we propose lines of future research to understand mobile payment infrastructure evolution based on a multi-perspective analysis.

\section{Related work}

According to Dahlberg et al. [5], most papers published around mobile payments cover technical issues (e.g., security, protocols, systems architectures), or consumer-centric studies (e.g., adoption). This rather limited and fragmented scope could be partly explained by the recent emergence of mobile payment research. Due to the increased interest we can expect more diversity in the next years while research in this domain matures.

Based on [5] we posit that there is a lack of multiperspective research that is needed to obtain a holistic view of payment system adoption and evolution. In addition, we need to conduct research that follows more than just one perspective at a time. Few studies, in fact, have looked at mobile payment diffusion in a systemic manner. Most investigations covering the topic have been carried out by consulting or industrial organizations (see e.g., [19]). There is a real need to engage in rigorous, theory based and multi-perspective explanations of the diffusion of mobile payments.

As mentioned above, the consumer behaviors (i.e. the demand side of the market) have been well investigated. However, the other side of the markets (i.e., providers and merchants) needs more attention. Analyzing the dynamics of two-sided markets [17] such as electronic payment systems [6], from a multiple stakeholder perspective is required to better comprehend the diffusion process [12].

In addition, mobile payments are subject to network externalities [18]. In order to measure the value of the network, it is important to understand the dynamics of additional benefits brought by new users of the payment system. Both of the sides of the market (including consumers, merchants and providers) should be analyzed using network externalities.

The evolution of the industry structure [11] is also essential to better comprehend the environment in which mobile payment solutions need to be embedded. A careful analysis of the context is required as factors of success or failure are strongly related to the industrial environment.

Another important aspect is the internal organization and business logic of the mobile payment solution. One way to analyze this dimension is to look at the business model. Since business models of mobile payment solutions are heterogeneous, we need to analyze them along multiple dimensions to verify their alignment with the environment. Osterwalder and Pigneur have proposed an framework to describe and analyze business models [14] involving four elements. First, the Market focuses on the target customers and the channels to reach them. Second, we need to look at the Value Proposition, which comprises the service and the value perceived by the target customers. Third, to describe the technical issues, we use an Infrastructure perspective, and, finally, fourth, we discuss the Financial aspects (i.e., costs and revenues).

After identifying all these perspectives we selected a number of frameworks from the mobile payment literature that cater for these dimensions. To take into account the economics of mobile payments, $\mathrm{Au}$ and Kauffman [1] have proposed a framework using economic theories such as network externalities, consumer choice and demand, switching costs, complementary goods, IT value, and economics of technology adoption and diffusion (see Figure 1).

Then, in terms of industry structure and strategy, we found a framework by Dahlberg et al. [5] (adapted from $[8,4,7])$. 


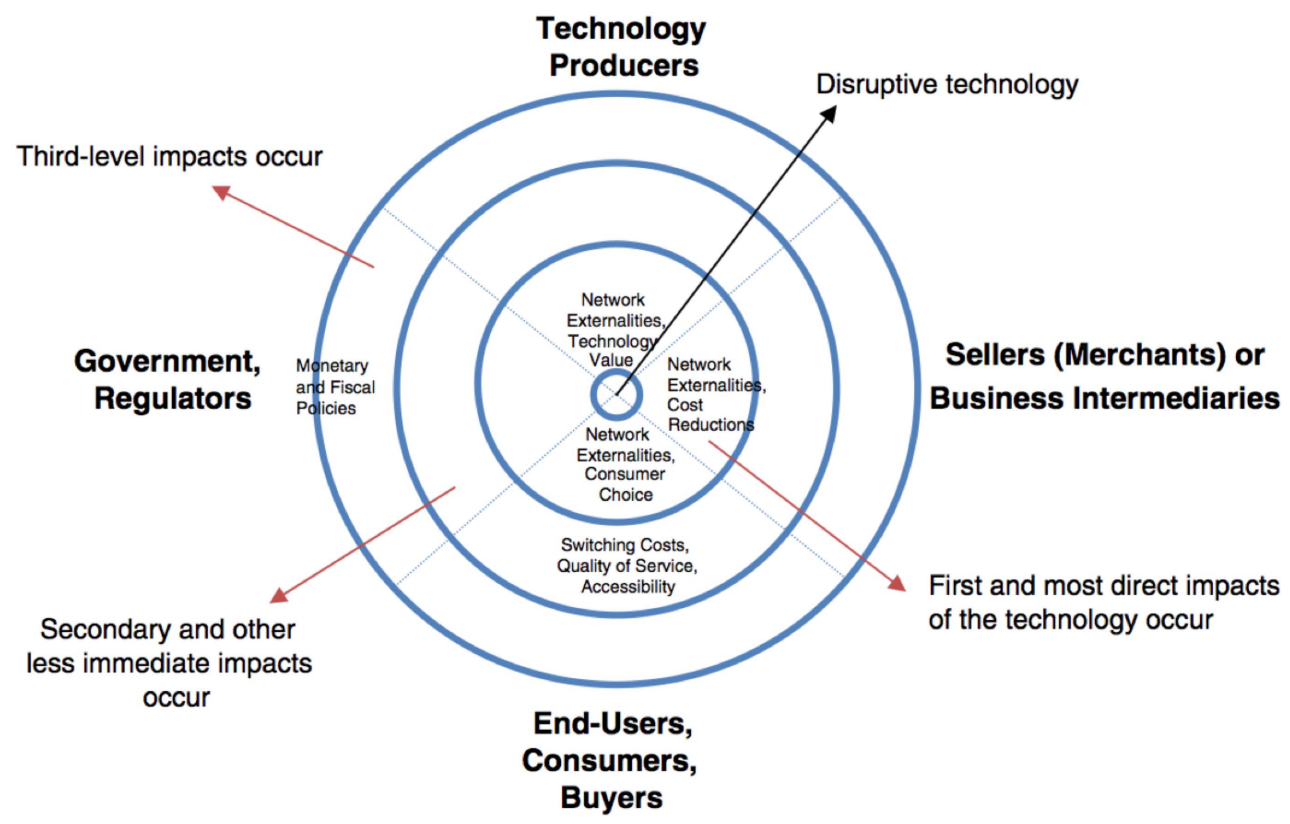

Figure 1. Framework proposed by Au and Kauffman [1]

This framework combines the five forces model [16] and the generic contingency theory $[9,15,20]$ (see Figure 2). Porter's competitive factors help analyze the competitive dynamics of the industry. The contingency factors relate to environmental issues that are out of the direct control for adopters. All these factors are supposed to have a major impact on the mobile payment adoption.

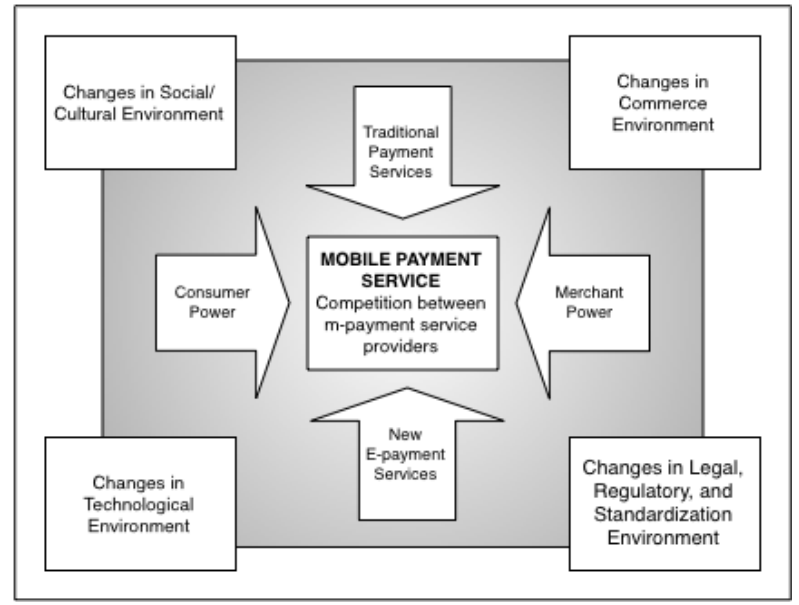

Figure 2. Framework proposed by Dahlberg et al. [5]

Another framework by Dahlberg et al. [3] deals with how to analyze mobile payment solutions (Figure 3 ). This framework provides several complementary perspectives to the ones already presented. A special focus here is given to resource based and resource dependent analysis affecting adopter behaviors. Furthermore, the framework includes issues related to business/economic and institutional factors.

\section{Mobile Payment cases in Switzerland}

\subsection{Data collection and analysis}

We selected three visible and relevant mobile payment initiatives in the Swiss market. These cases illustrate well the efforts that have been carried in the past years in Switzerland. We analyzed the cases using materials collected during our previous research [13] and by obtaining new secondary sources (i.e., news, articles). Moreover, we contacted and interviewed key experts, who had been involved in the design and implementation of mobile payments in these cases. We analyzed the case data using the three frameworks to code the data. Furthermore, we described the business models underlying the cases using the four perspectives of the Business Model Ontology by Osterwalder and Pigneur [14].

The first case is the m-Maestro project, which was a common effort between the major Swiss companies to enable the Maestro card for m-commerce purchases and the top up of mobile phone prepaid accounts. The second case is the first European initiative to offer an $\mathrm{m}$-commerce platform compliant with the "Verified by Visa" security standard. Finally, the last case is a mobile payment solution initiated by a major financial institution called PostFinance. 


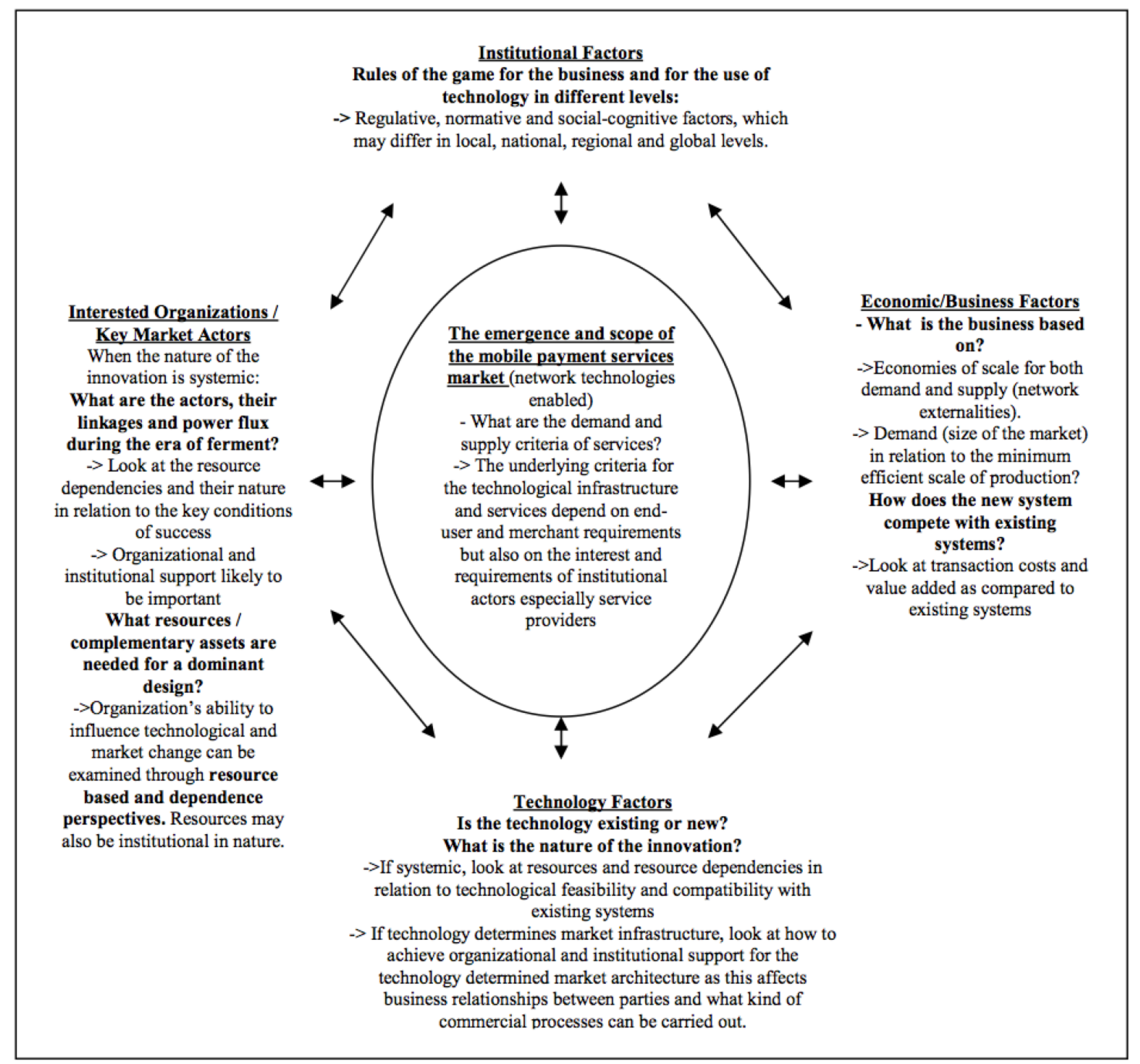

Figure 3. Framework proposed by Dahlberg et al. [3]

None of these solutions have been successful so far. The m-Maestro project was never launched. It failed at the stage of design (which was mostly on paper). "Verified by Visa" platform has not seen new developments since the announcement of its implementation (failed after implementation). PostFinance abandoned the solutions after the first trial (failure after a real world test). Since the trial reported here PostFinance has launched a new scheme. This is more focused and less ambitious and gives up the goal of developing an extensive payment infrastructure as it mostly support remote purchases of digital goods (e.g. news, ticketing).

We performed the same analysis on each of the three cases, but due to space limitation, we describe only one of the cases in detail (i.e., PostFinance). For completeness, we provide a brief explanation of the reasons why the two other schemes failed at different stages to highlight our dynamic approach.

\subsection{Description of the first two cases}

3.2.1. The m-Maestro project. The m-Maestro project was launched in the early 2000s. The objective was to enable the Maestro card (i.e., debit card) to pay for $\mathrm{m}$-commerce transactions. The motivation was driven by the national mobile network operators (MNO), which wanted to have secure and convenient means to top up their prepaid accounts. Back then, prepaid accounts were usually charged using scratch cards. These cards were mostly sold in kiosks. Unfortunately, these kiosks took a $10 \%$ commission for each scratch card sold. Compared to the fees of traditional payment means such as debit and credit cards, these scratch cards were quite inefficient and not profitable for the MNOs. Since the Maestro card was getting more popular, MNOs were thinking about a solution based on this debit card. Moreover, by extension, this card could be used to buy digital or 
physical goods without charging the monthly MNO bill. The expected benefit was that the monthly bill, which contained voice and data consumption information, would not be "polluted" with extra information about third-party financial transactions. Furthermore, the MNOs wanted to benefit from the risk management provided by the banks. On the side of the financial institutions, this project mainly aimed at creating a new channel for the Maestro card.

As the project faced several technical challenges and priorities changed the trial was never launched despite the MNOs' initial enthusiasm. Part of the failure could also be explained by the fact that the project took place too early. Looking back, the market was likely to be unprepared for such an initiative. The volume of transaction was too low, which made the cost of the design, implementation, and operation hard to justify. As a result, without the support of the whole industry, the m-Maestro project was abandoned. Nothing happened after the first round of nonfulfillment. Despite the failure, the project was an excellent source of learning for the Swiss banking and mobile industries. Most of the experts involved during the trial are still active in the mobile payment area.

3.2.2. Secure Mobile Commerce - Visa. In Summer 2006, Corner Bank and its partners announced the first European mobile commerce solution using the secure standard "Verified by Visa". The solution has been named Secure Mobile Commerce. The basic idea was that the Visa card could be used securely for mcommerce transactions.

Corner Bank, one of the major Swiss credit card issuers, offered to their cardholders the possibility to use their Visa cards to make secure payments in mobile shops. Thanks to the partnership with Sunrise (a Swiss $\mathrm{MNO}$ ), Corner Bank cardholders could use the scheme to pay in a mobile music store (musicfinder).

The deployment of the solution required the participation of companies with diverse knowhow. Telekurs Multipay was in charge of the acquisitions and the linkages of mobile shops to Visa payment system. Datatrans developed the interface between the mobile shop checkout page, and Telekurs created the payment system. Arcot, a payment security specialist, provides the authentication mechanisms for a secure "Verified by Visa" transaction with the mobile phone. Finally Crealogix was responsible for the development of the mobile shop with the extension of the musicfinder. The service was never adopted widely due to its limited focus and benefits.

\subsection{Mobile Payments by PostFinance}

The most widely known mobile payment scheme in Switzerland comes from PostFinance. PostFinance tends to be generally a first mover in many fields related to retail banking. Furthermore, it dominates the payment traffic in Switzerland with more than 3.3 million accounts ${ }^{1}$ (in a country of about 7.5 million habitants). This makes PostFinance a strong player in the mobile payment arena. It has large customer and merchant base for daily payments (about $60 \%$ of the market share).

PostFinance has launched two distinct mobile payment initiatives. The first one consisted of a trial for proximity payments, and the second one a remote mobile payment solution to pay for online purchases. For the purpose of this research, we primarily focus on the first trial launched in 2005 in the city of Bern. We selected this trial, because it is the major attempt to propose proximity payments using a mobile phone. Furthermore, in case of the success of the trial, the tried out scheme was supposed to be launched nationally.

To characterize the internal organization of the trial, we use a simplified version of the Business Model Ontology [14]. The instantiation of the framework enabled us to better understand the business logic underlying the PostFinance's solution. This step was essential in order to evaluate the alignment of the business model with the environment. This evaluation would then help us unveil a number of internal factors that can lead to success or failure.

The market PostFinance was targeting were holders of post accounts, and user of mobile phones. The objective was to link accounts to mobile phone numbers. Their target customer segment was fairly large. For the trial, they tested the scheme only with employees of the involved companies (about a thousand participants).

The value proposition was about offering a convenient and secure way to pay for physical goods using a mobile phone. PostFinance customers would have more flexibility by having an extra means of payment. On their side, the merchants saw opportunities to improve their payment process by enhancing their customer relationship management by having the possibility to offer new types of personalized coupons.

In terms of infrastructure, PostFinance collaborated with Unisys and Gavitec to design the payment solution. Due to the proposed solution, PostFinance could bypass the MNOs by using them only as carriers. PostFinance also managed to involve various partners in the retail industry. During the trial, merchants accepted the payment instrument at twelve locations in Bern. The list of participants comprised of two largest Swiss retailers (Migros, Coop), McDonald's, two

\footnotetext{
${ }^{1}$ Key figures 2007 from PostFinance website
} 
electronic retailers (Interdiscount, Mobilezone), the Postshops, and the Swiss national railways (SBB). An additional payment terminal was added at the point of sale of each participant's shops in Bern. The terminal enabled the merchant to read a special bar code (Data Matrix) received via text message on the buyer mobile phone. The payment process could be described as follows: The payment process is initiated at the point of sale (POS) by the consumer by (i) scanning the barcode stuck on the back of the mobile phone and (ii) typing a PIN code on a terminal. Then, (iii) the merchant enters the amount of the purchase on the same terminal using a small externally attached keyboard. From there, (iv) the information is transmitted to the PostFinance m-payment platform. A few seconds later, if all checks are cleared, (v) the consumer gets an SMS with a barcode and some information concerning the purchase (name of the merchant, the amount of the purchase, and the date). If the consumer agrees, (vi) the barcode in the SMS has to be scanned by the terminal to conclude the transaction. Finally, (vii) the terminal confirms the purchase and the consumer gets a receipt of the purchase. The payment amount is debited in real time from the customer's PostFinance account.

As the trial was an extension of the Postcard, the major impacts on the financial aspects remained in the cost of the infrastructure deployed, the extra cost of issuing additional payment means, and advertising to increase the general awareness of mobile payments. Expected revenues come from transaction fees paid by the merchants, a licensing fee that other financial institutions would pay to join and use the scheme, and finally potential fees from mobile coupons. Moreover, the positive impacts on the purchase experience could motivate customers to spend more.

\section{Analysis of the three Swiss cases}

As noted, several researchers have identified the need of a multi-perspective analysis and to this end have proposed frameworks that need to be taken into account when analyzing mobile payment diffusion. In this section, we use these frameworks as alternative filters to unveil potential factors of failure.

\subsection{Short analysis of the first two cases}

Due to space limitations we can only provide a short description of what were the factors which made m-Maestro and "Secure Mobile Commerce" fail. For m-Maestro, the lack of a strong actor who could push the solution forward by forcing/motivating the other parties to collaborate was a killing factor. Under these conditions any mobile payment solution would have difficulties to be launched.

Despite a relatively good technology and business case, the actors failed to find a solution which would match their individual utilities (i.e., Pareto equilibrium). Because of the problems of coordination the solution did not succeed and was abandoned. As we could observe, m-Maestro mostly failed because of the lack of support from different stakeholders.

On the contrary, the "Secure Mobile Commerce" of Corner Bank was able to gather and motivate all the actors necessary to provide the solution. However, it failed to involve both consumers and merchants. In this case, we had some powerful actors willing to launch a solution. Unfortunately, they did not solve the issue of two-sided markets, which is to involve both the demand and supply side of the market to get the wagon rolling. They failed to generate network externalities though appropriate actor incentives either for the customers or the merchants to join.

\subsection{PostFinance analysis}

4.2.1 Economic analysis of PostFinance solution. To conduct an economic analysis of PostFinance solution, we use the first framework proposed by $\mathrm{Au}$ and Kauffman [1]. This framework looks at the mobile payment market using an economic perspective (Figure 1). The first step is to identify different stakeholders of the market. The technology producers are the firms or organizations providing the mobile payment product or service. They symbolize the supply-side of the market. In our case, PostFinance, Gavitech, and Unisys are the technology producers. There are also the users, consumers, and buyers. On the other side there are the merchants that participate in the mobile payment scheme. In addition, we have the government and regulators which control and regulate the market.

In their framework, Au and Kauffman also include different levels of impact on the stakeholders. The most direct impacts are related to network externalities. In fact, in order for PostFinance's scheme to be successful, a large number of customers and merchants need to adopt the payment scheme. By involving the major retailers (Migros and Coop) in Switzerland, PostFinance sought to create a fairly large network of points-of-sale (POS), which would accept mobile payments and consumers would have many places where to pay with their mobile phone. The "chickenand-egg" problem would be partly solved by having a large merchant base before offering the solution to the consumers. With more consumers and merchants on board, PostFinance would increase the value of the payment solution. 
Based on their preferences for payments in specific contexts, the consumers would have an additional possible payment instrument. The choice will mostly depend on which payment solution maximizes the utility of the consumers. The consumers will seek the best option in the range of the options available. In other words, the consumers will have to decide which payment instrument is the most suitable and brings the best value to the transaction. The value perceived could be financial (e.g., discount, loyalty scheme with rewards), practical (e.g., speed, convenience), or psychological (e.g., trust, fashionable). Going back to PostFinance scheme it is not clear what would have been its value for the consumers. To change customer behavior towards payments, a clear added-value should have been perceived when using the new scheme. This rule applies also for the merchants as they expect benefits or incentives when adopting a new payment scheme. In the PostFinance case the value perceived for mobile payments was probably not great, because the technology deployed was not more efficient (faster) than the traditional payment with cards. However, the merchants saw an opportunity to offer a personalized loyalty scheme to their customers. The scheme would allow merchants to send coupons directly to the mobile phone of their customers. This additional service bundled with the payment solution appeared promising in order to increase the value for the merchants and the consumers.

By providing a new electronic payment solution, PostFinance would reduce the number of cash-based transactions. As these transactions are quite expensive, there might be some cost reduction related to the adoption of mobile payments. This is the case only, if the transaction fees are not too high. Since PostFinance is offering mobile payments based on their direct debit scheme, the transaction fees would not differ from the use of the PostCard.

Other secondary impacts comprise issues such as switching costs, quality of service and accessibility. Once the solution has created network externalities, then, the providers hope that customers will join in mass. Switching costs could be seen as a barrier for adoption. However, the solution designed should limit the financial (e.g., cost of the solution), psychological, and practical hurdles for PostFinance customers. In order to fully satisfy the consumers, PostFinance had to provide a secure and reliable payment solution. Later impacts (third-level) could be related to regulations and policies that have to be put in place in order to control the monetary and fiscal issues. PostFinance did not have problems since their mobile payment solution was just an additional channel to access their existing payment system. They were compliant with all the regulation in place.
4.2.2 PostFinance: a strategic analysis. For the strategic and environment analysis, we use the framework proposed by Dahlberg et al. [5]. Porter's competitive factors help us to analyze the competitiveness of the industry surrounding PostFinance. The contingency factors relate to environmental issues that are beyond the direct control of PostFinance.

We start the analysis by looking at the contingency factors that have great influence on the Swiss mobile payment market. In terms of social and cultural environment, the Swiss market is quite traditional and sometimes considered conservative. In terms of payments, Swiss consumers and merchants use the same payment instruments as in other Western countries. PostFinance tried to take advantage of the widespread use of mobile phones and its widely adopted PostCard (i.e., debit card). The combination of both technologies seemed promising. However, Swiss consumers might not be ready for such an important evolution of their current payment instruments.

Switzerland, as well as other Western countries, has been exposed to changes in the commercial environment with the emergence of e-commerce and other advances in mobile telecommunication. In the convergence of the banking and telecommunication industry we have witnessed the development of mobile banking platforms. Moreover, mobile network operators have been pushing new mobile services and content through their mobile portals. All of these evolutions made mobile payments look like a valuable addition to the existing portfolio of services. This opens new opportunities for PostFinance to innovate in the payments.

In terms of technology, Switzerland has good telecommunication, banking, and payment infrastructures. On the industry side, most of the technology building blocks are available to launch a mobile payment scheme. However, the consumer mobile phones capabilities are still limited in offering proximity mobile payments. Therefore, PostFinance had to find the best available technologies compatible with the current set of consumer's mobile phones. They decided to use SMS for the payment scheme, as it was a standard implemented in all mobile phones on the market. Near field communication (NFC), a technology similar to RFiD standards, would have been clearly a much better choice for the type of payment scheme they launched. Unfortunately, it was not available in the market and is still awaited today.

Regulation in Switzerland has not been a real issue. Besides banking license regulation and electronic money directives, PostFinance did not have to worry with its mobile payment scheme, as they are already compliant with all regulations. 
Standardization in mobile payments is clearly a critical issue. In Switzerland, the market is too small to offer different standards to consumers. This is the reason why PostFinance wanted to establish its solution as a "de-facto" open standard. The objective was that other financial institutions could be able to join this interoperable scheme.

Consumers have the power to adopt a new payment scheme. They can also express needs and therefore, frame the requirements for payment solutions that would suit their behaviors. For PostFinance, it was important that consumers were willing to accept the use of mobile payments. However, past experiences in payments showed that consumers did not have a great influence on the design of solutions. Most of the payment instruments were imposed from the providers without a clearly defined demand from the consumers.

In order to facilitate a wide adoption and generate network externalities, merchants need to be involved in the deployment of mobile payments. Without the support of merchants, the solution would have more difficulties to become accepted in the market. PostFinance understood this issue well as they involved the most influent and important retailers in Switzerland. Merchants have some bargaining power as the additional payment instrument is not indispensable. Since they have to make substantial investments in order to upgrade their current point of sales systems they can negotiate lower transaction fees.

Traditional payments such as cash, debit and credit cards represent competing solutions that mobile payments need to displace in the proximity payment area. PostFinance had to find a way to provide more value than existing payment solutions. By offering more capabilities such as mobile couponing, merchants and consumers could be interested to adopt PostFinance's scheme. This would add value that could make a difference when compared to traditional payments. Unfortunately, PostFinance failed to provide better value.

New electronic payment services such as Paypal could have an impact on the adoption. However, the position of the proximity payment solution of PostFinance was not likely to be threatened by remote payment solutions. However, depending on how the market evolves, these online payment methods could reach the mobile phone. In fact, Mobile Paypal was launched few months after PostFinance solution. Moreover, with the emergence of mobile phone, such as the iPhone, the mobile Internet is becoming a new channel that could be exploited.

Looking at the competition in the Swiss mobile payment market, PostFinance had an ideal position to impose their solution. The other major financial institutions in Switzerland do not consider mobile payments as a profitable business. Since PostFinance is the largest payment service provider in Switzerland, mobile payments could become an additional competitive weapon for them. Mobile network operators are also interested in this market. However, the tendency has been towards collaboration between the telecom and the financial industries. PostFinance mobile proximity payments did not have any competing alternative. Therefore, PostFinance could gain a first mover advantage [10] by imposing their solution as a standard.

4.2.3 Analysis of PostFinance: a resource perspective. The third framework [3] focuses on resource based and resource dependent perspectives.

One of the aspects therein is to analyze the actors, their linkages, and their power already covered with the previous framework. However, it is interesting to examine the institutional support that PostFinance needed in order to succeed. Despite its partnership with other organizations (e.g., Swisscom), PostFinance had difficulty in convincing other actors to join the mobile payment scheme. Most of the other players adopted a wait-and-see position. PostFinance had to take all the risks in the hope of eventually getting a competitive and first mover advantage. Since PostFinance operates its own payment network, the most important resources were already available. Crucial elements for the deployment of the infrastructure were the payment terminals. Retailers had to add another terminal to their existing point of sale infrastructure. Without the support of the merchants, PostFinance would have had a significant problem to solve.

PostFinance integrated its mobile payment scheme into the existing infrastructure. The objective was to launch the scheme with a minimal infrastructure change. On the side of the consumers, the mobile payment scheme was designed to be compatible with most existing mobile phones. Instead of introducing new technology, PostFinance used current technologies to propose a new system.

The Swiss market is not large enough to support several payment schemes. PostFinance hoped that by proposing the first system others would have no other choice but join. Indeed, PostFinance was trying to enable a new channel for its own payment system. In the mobile payment proximity area, there were no direct competitors. PostFinance had a good position to impose itself as the leader. To validate findings we also interviewed the mobile payment project manager of PostFinance. He confirmed that our findings were relevant and explained well the outcome of the failed trial. PostFinance's trial was discontinued, as several key factors were not satisfying (Table 1). 


\section{Conclusion and discussion}

The juxtaposition of the three frameworks helped us to conduct a comprehensive analysis of the failure of mobile payment diffusion in Switzerland using multiple perspectives: economic, strategy, resource based, and behavioral. The applied frameworks were complementary with some redundancy.

In general, the account of the diffusion process and factors that influence it is rich and relatively complete. To wit, we were able unveil most factors that led the implementations and designs to fail in the early stages.

The analysis shows, however, that each framework misses some critical factors. First, the high level of abstraction of these frameworks makes them difficult to apply in concrete situations ex ante. Second, none of the frameworks encompasses the dynamics of the diffusion and only provides a static view of mobile payment diffusion trajectory. Even though, they can be instantiated several times during the study period and comprise of several dynamic factors, they are not inherently dynamic: they do not propose a sequence of stages where the analysis needs to be performed differently. At each stage, however, we detected different factors that impede the progress. Therefore the frameworks need to be augmented with a dynamic model of the diffusion stages as shown in Table 1. Third, the frameworks did not observe behavioral and coordination challenges associated with embedding the mobile payments in local contexts and the need for scaling the service for growth. Though PostFinance met most positive conditions for introducing a viable service based on its dominant position and active involvement of major retailers, it failed to provide additional value for consumers and local merchants. In contrast, PostFinance faced significant difficulties in finding a feasible trade-off between interoperability and the ease of use for consumers. It had to sacrifice the ease of use for interoperability and scale, which resulted in a clumsy solution, which did not fit with the physical environment and the behaviors associated with payments in local stores. Consumers have deeply ingrained habits to pay in certain ways with associated physical behaviors. Many criticized the chosen solution as the payment terminals were too cumbersome and

Table 1. Dynamic model of the diffusion stages of a mobile payment solution

\begin{tabular}{|c|c|c|c|c|}
\hline Phases & Main evidence from the cases & Au and Kauffman [1] & Dahlberg et al. [5] & Dahlberg et al. [3] \\
\hline $\begin{array}{l}\text { 1. Build an alliance } \\
\text { between MNO and } \\
\text { Financial institutions }\end{array}$ & $\begin{array}{l}\text { m-Maestro: they did not reach a } \\
\text { consensus. It failed to convince } \\
\text { every actor. } \\
\text { PostFinance: they were able to } \\
\text { bypass the MNOs by using them as } \\
\text { simple carrier. They did not need } \\
\text { other financial institutions as they } \\
\text { already operate their own payment } \\
\text { network. }\end{array}$ & $\begin{array}{l}\text { - Stakeholder } \\
\text { identification }\end{array}$ & $\begin{array}{l}\text { - Competition between } \\
\text { the providers } \\
\text { - New and competing } \\
\text { e-payment and } \\
\text { traditional systems } \\
\text {-> PostFinance: they } \\
\text { have a great position } \\
\text { to compete and lead } \\
\text { the market }\end{array}$ & $\begin{array}{l}\text { - Interested } \\
\text { Organizations / Key } \\
\text { Market Actors } \\
\text { PostFinance: } \\
\text { Difficulties to } \\
\text { involve and get the } \\
\text { support of the other } \\
\text { service providers }\end{array}$ \\
\hline $\begin{array}{l}\text { 2. Involve the sellers and } \\
\text { business intermediaries } \\
\text { side (i.e., merchants) in } \\
\text { the development and } \\
\text { deployment of the service. } \\
\text { Build a sufficient supply } \\
\text { in two-sided markets. }\end{array}$ & $\begin{array}{l}\text { "Secure Mobile Commerce": they } \\
\text { did not involve enough actors } \\
\text { (merchants) to generate the network } \\
\text { effects. } \\
\text { PostFinance: they involved the } \\
\text { major merchants of Switzerland, } \\
\text { which created an important } \\
\text { network. }\end{array}$ & $\begin{array}{l}\text { - Network externalities } \\
\text { - Cost reduction -> } \\
\text { PostFinance: } \\
\text { merchants could } \\
\text { decrease the number } \\
\text { of cash-based } \\
\text { transactions }\end{array}$ & $\begin{array}{l}\text { - Merchant power -> } \\
\text { PostFinance: } \\
\text { Merchants could } \\
\text { bargain to reduce the } \\
\text { transaction fees }\end{array}$ & $\begin{array}{l}\text { - Economic/Business } \\
\text { Factors } \\
\text { - Interested } \\
\text { Organizations / Key } \\
\text { Market Actors }\end{array}$ \\
\hline $\begin{array}{l}\text { 3. Provide an adequate } \\
\text { value for the consumers to } \\
\text { join the service. Generate } \\
\text { incentives to create } \\
\text { demand in two-sided } \\
\text { markets. }\end{array}$ & $\begin{array}{l}\text { "Secure Mobile Commerce": the } \\
\text { low number of point of acceptance } \\
\text { did not create value for consumers. } \\
\text { PostFinance: they failed to create a } \\
\text { real value for consumers (compared } \\
\text { to existing systems) }\end{array}$ & $\begin{array}{l}\text { - Consumer choice } \\
\text { - Switching cost -> } \\
\text { PostFinance: existing } \\
\text { customer would not } \\
\text { have to pay extra } \\
\text { - Quality of service } \\
\text { - Accessibility } \\
\end{array}$ & $\begin{array}{l}\text { - Customer power } \\
\text { - Changes in } \\
\text { Social/Cultural } \\
\text { Environment -> } \\
\text { Swiss consumers are } \\
\text { relatively conservative }\end{array}$ & $\begin{array}{l}\text { - Economic/Business } \\
\text { Factors }\end{array}$ \\
\hline $\begin{array}{l}\text { 4. Involve the } \\
\text { manufacturers to scale the } \\
\text { system and offer } \\
\text { interoperability and ease } \\
\text { of use. Build up } \\
\text { interoperable standards for } \\
\text { connectivity and } \\
\text { transactions }\end{array}$ & $\begin{array}{l}\text { PostFinance: they involved } \\
\text { different technology providers and } \\
\text { integrators. However, the mobile } \\
\text { phone manufacturers did not } \\
\text { participate. They ended up with a } \\
\text { non-standard solution. A Swiss } \\
\text { interoperable standard is key in } \\
\text { order to succeed. }\end{array}$ & $\begin{array}{l}\text { - Technology value } \\
\text { - Accessibility }\end{array}$ & $\begin{array}{l}\text { - Changes in } \\
\text { Technological } \\
\text { Environment -> } \\
\text { Emergence of e-/m- } \\
\text { commerce brings a } \\
\text { new opportunities for } \\
\text { mobile payments }\end{array}$ & $\begin{array}{l}\text { - Technology factors } \\
\text {-> PostFinance: } \\
\text { they ignore relevant } \\
\text { technology factors } \\
\text { due to infrastructural } \\
\text { constraints }\end{array}$ \\
\hline $\begin{array}{l}\text { 1-4. Deal with regulatory } \\
\text { issues (restrictions, } \\
\text { incentives, obligations) }\end{array}$ & $\begin{array}{l}\text { PostFinance: they were already } \\
\text { compliant with all the current } \\
\text { regulations. }\end{array}$ & $\begin{array}{l}\text { - Monetary and fiscal } \\
\text { policies }\end{array}$ & $\begin{array}{l}\text { - Changes in Legal, } \\
\text { regulatory, and } \\
\text { standardization } \\
\text { environment }\end{array}$ & $\begin{array}{l}\text { - Institutional } \\
\text { factors }\end{array}$ \\
\hline
\end{tabular}


bulky, and the sticker in the back of the mobile phone looked just too cheap. Likewise, the payment process was not simpler and faster than the use of the traditional PostCard. The solution therefore met with resistance both at the consumer and local merchant side. Partially this was due to the lack of adequate standardization for introducing technical solutions that would allow for simple local behaviors. The original design choices were made in order to enable the largest number of customers to participate in the payment scheme. Yet, if standardized and cheaper NFC technologies had been made available, the proposed solution would have probably worked better.

As discussed above, the use of frameworks to study the environment offered an occasion for expansive learning. However, without the description of the business models using Osterwalder and Pigneur's ontology [14], we would not have been able to differentiate business logics associated with different cases. By having a better overview of the business models, we could better evaluate the fit between the solutions and the environment.

Future research is needed to formulate a more complete framework grounded in the richer process data of mobile payment diffusion trajectories. We plan to expand the current framework with findings from the study of actual diffusion processes. In Table 1, we outline the phases of mobile payment diffusion and suggest which factors are likely to promote success in different stages based on the findings from the cases.

We also aim to conduct a set of more encompassing case studies in several national and industry contexts. In this way, we hope to unveil a more complete set of factors that influence the success of payment solutions in a given environment. By aggregating findings from these studies, we expect to solicit a more encompassing suite of explanatory patterns in the diffusion of mobile payments. Another direction is to apply the proposed model to investigate other mobile services including location-based services or mobile TV. These solutions share similar characteristics including two-sided markets, importance of the network externalities, complex and embedded technology, coordination challenges across industries raising significant standardization challenges, and thus are mostly likely driven by the same set of factors. However, these services differ as they create new markets and new streams of revenues, which is not the case with mobile payment solutions where the solution directly competes with existing solutions.

\section{References}

[1] Y. Au and R. Kauffman. The economics of mobile payments: Understanding stakeholder issues for an emerging financial technology application. Electronic Commerce Research and Applications, 7:141-164, 2008.

[2] D. Balaban. Japan's mobile wallets fail to inspire - yet. Card Technology, 13-04-2007, 2007.

[3] T. Dahlberg, M. Huurros, and A. Ainamo. Lost opportunity why has dominant design failed to emerge for the mobile payment services market in Finland. 41st Hawaii International Conference on System Sciences, Jan 2008.

[4] T. Dahlberg and N. Mallat. Mobile payment service development - managerial implications of consumer value perceptions. The Tenth European Conference on Information Systems (ECIS), 2002.

[5] T. Dahlberg, N. Mallat, J. Ondrus, and A. Zmijewska. Past, present and future of mobile payments research: A literature review. Electronic Commerce Research and Applications, 7(2):165-181, May 2008.

[6] D. Evans and R. Schmalensee. Paying with plastic : the digital revolution in buying and borrowing. The MIT Press; 2nd edition, 2005.

[7] R. Javalgi and R. Ramsey. Strategic issues of e-commerce as an alternative global distribution system. International Marketing Review, 18(4):376-391, 2001.

[8] C. Jayawardhena and P. Foley. Changes in the banking sector - the case of Internet banking in the UK. Internet Research, 10(1):19-31, 2000.

[9] P. Lawrence and J. Lorsch. Organisation and Environment. Irwin, Homewood, Illinois, 1967.

[10] M. Lieberman and D. Montgomery. First-mover advantages. Strategic Management Journal, Summer Special Issue 9:41-58, Jan 1988.

[11] R. Nelson and S. Winter. An Evolutionary Theory of Economic change. Harvard University Press, Cambridge, MA., 1982.

[12] S. Oh, H. Lee, S. Kurnia, R. Johnston, and B. Lim. A stakeholder perspective on successful electronic payment systems diffusion. 39th Hawaii International Conference on System Sciences, 2006.

[13] J. Ondrus and Y. Pigneur. Cross-industry preferences for mobile payments development in Switzerland. Electronic Markets, 17(2):142-152, 2007.

[14] A. Osterwalder and Y. Pigneur. An e-Business Model Ontology for Modeling e-Business. 15th Bled Electronic Commerce Conference, 2002. .

[15] C. Perrow. A framework for the comparative analysis of organizations. American Sociological Review, 32(2):194208, 1967.

[16] M. Porter. Competitive Strategy. Free Press, New York, 1980.

[17] J. Rochet and J. Tirole. Platform competition in twosided markets. Journal of the European Economic Association, 1(4):990-1029, Jan 2003.

[18] C. Shapiro and H. Varian. Information Rules: A Strategic Guide to the Network Economy. Harvard Business School Press, Boston, MA, 1999.

[19] K. Taga and J. Karlsson. Arthur D. Little Global MPayment 2004. Technical report, Arthur D. Little's Telecommunications, IT, Media \& Electronics (TIME) Practice, Vienna, Austria, 2004.

[20] J. Thompson. Organizations in Action. McGraw-Hill, New York, NY, 1967. 